\title{
Correlation between Body Mass Index and Waist Circumference in Patients with Metabolic Syndrome
}

\author{
Marcin Gierach, ${ }^{1,2}$ Joanna Gierach, ${ }^{2}$ Marlena Ewertowska, ${ }^{1}$ \\ Adam Arndt, ${ }^{1}$ and Roman Junik ${ }^{1}$ \\ ${ }^{1}$ Department of Endocrinology and Diabetology and Laboratory of Nuclear Medicine, Nicolaus Copernicus University in Torun, \\ Collegium Medicum in Bydgoszcz, 85-094 Bydgoszcz, Poland \\ ${ }^{2}$ Internal Ward in District Hospital in Wabrzezno, 87-200 Wabrzezno, Poland
}

Correspondence should be addressed to Marcin Gierach; marcin_gierach@wp.pl

Received 18 September 2013; Accepted 30 December 2013; Published 4 March 2014

Academic Editors: T. Gaillard, Y. B. Lombardo, A. Saxe, and N. Tentolouris

Copyright (c) 2014 Marcin Gierach et al. This is an open access article distributed under the Creative Commons Attribution License, which permits unrestricted use, distribution, and reproduction in any medium, provided the original work is properly cited.

\begin{abstract}
Metabolic syndrome is defined as a group of coexisting metabolic risk factors, such as central obesity, lipid disorders, carbohydrate disorders, and arterial hypertension. According to the 2005 IDF criteria, subsequently revised in 2009, abdominal obesity is identified as the waist circumference of $\geq 80 \mathrm{~cm}$ in women and $\geq 94 \mathrm{~cm}$ in men. It is responsible for the development of insulin resistance. The aim of our study was to demonstrate a correlation between waist circumference (WC) and body mass index (BMI) in patients with metabolic syndrome in relation with hypertension, lipid disorders, and carbohydrate disorders. A cross-sectional two-site study was conducted in the Kuyavian-Pomeranian Voivodeship for 24 months. The study group consisted of 839 patients with diagnosed metabolic syndrome: 345 men (41.1\%) and 494 women (58.9\%) aged 32-80. In the study group, WC was found to be significantly correlated with BMI $(R=0.78, P<0.01)$. The presence of overweight in men $\left(\mathrm{BMI} 25,84 \mathrm{~kg} / \mathrm{m}^{2}\right)$ and even normal body weight in women (BMI 21,62 kg/m ${ }^{2}$ ) corresponds to an increased volume of visceral tissue in the abdomen. Introduction of primary prophylaxis in those people to limit the development of diabetes mellitus type 2 and cardiovascular diseases should be considered.
\end{abstract}

\section{Introduction}

Metabolic syndrome is defined as a group of coexisting metabolic risk factors, such as central obesity, lipid disorders, carbohydrate disorders, and arterial hypertension [1-5]. Those factors increase the risk of developing cardiovascular diseases of atherosclerotic etiology and diabetes mellitus type $2[1,5-$ 9], which are the main cause of premature deaths among most of the European and US population [10].

The number of patients with metabolic syndrome increases with age. In the US population, the percentage of such patients above the age of 20 is approximately $23 \%$, while the percentage of such patients above 60 is approximately $40 \%$ [11].

Abdominal obesity is the major disorder constituting a base for the development of metabolic syndrome. BMI is the simplest, most practical, and most widely used system of indexing body weight. It is defined as body weight (in kilograms) divided by the square of body height (in metres). The index divides patients into appropriate categories: underweight, normal weight, overweight, and obese. Even though BMI is commonly used for monitoring the occurrence of obesity in the population, it has numerous limitations. It does not provide any information on the distribution of the adipose tissue in the organism. BMI is a calculated statistical value which does not take into consideration physiological differences in the proportions between the adipose, osseous, and muscular tissues [11]. Besides, its value is affected by sex, age, constitution, and training. Evidence from the conducted studies has revealed that abdominal obesity (assessed based on the waist circumference) plays a very important role in the development of metabolic disorders and in the assessment of cardiovascular risk. According to the 2005 IDF criteria, subsequently revised in 2009 , abdominal obesity is identified as the waist circumference of $\geq 80 \mathrm{~cm}$ in women and $\geq 94 \mathrm{~cm}$ in men. It is responsible for the development of insulin 
TABLE 1: General characteristics of the study group.

\begin{tabular}{lcccccc}
\hline & $n$ & Age (years) & Body weight $(\mathrm{kg})$ & Body height $(\mathrm{cm})$ & BMI $\left(\mathrm{kg} / \mathrm{m}^{2}\right)$ & Waist circumference $(\mathrm{cm})$ \\
\hline Total & 839 & $67.5 \pm 12.9$ & $84.9 \pm 17.8$ & $166.0 \pm 8.6$ & $30.7 \pm 5.6$ & $107.9 \pm 13.5$ \\
Women & $494(58.9 \%)$ & $70.6 \pm 11.3$ & $79.5 \pm 17.5$ & $161.1 \pm 5.8$ & $30.6 \pm 6.3$ & $105.8 \pm 14.6$ \\
Men & $345(41.1 \%)$ & $63.0 \pm 13.8$ & $92.5 \pm 15.1$ & $173.1 \pm 6.7$ & $30.8 \pm 4.4$ & $110.8 \pm 11.2$ \\
\hline
\end{tabular}

TABLE 2: Characteristics of the study group according to the components of metabolic syndrome.

\begin{tabular}{lcccc}
\hline & $n$ & Age $($ years $)$ & BMI $\left(\mathrm{kg} / \mathrm{m}^{2}\right)$ & Waist circumference $(\mathrm{cm})$ \\
\hline Total & 839 & $67.5 \pm 12.9$ & $30.7 \pm 5.6$ & $107.9 \pm 13.5$ \\
Abdominal obesity & $828(98.7 \%)$ & $67.4 \pm 13.0$ & $30.8 \pm 5.5$ & $108.2 \pm 13.2$ \\
Arterial hypertension & $796(94.9 \%)$ & $67.9 \pm 12.7$ & $30.8 \pm 5.7$ & $108.0 \pm 13.7$ \\
IFG & $208(24.8 \%)$ & $63.6 \pm 14.8$ & $30.3 \pm 5.2$ & $106.6 \pm 12.7$ \\
Diabetes mellitus type 2 & $491(58.5 \%)$ & $70.0 \pm 11.1$ & $31.2 \pm 5.8$ & $109.3 \pm 13.9$ \\
TG & $313(37.3 \%)$ & $63.8 \pm 13.7$ & $30.7 \pm 4.7$ & $108.0 \pm 12.7$ \\
HDL & $567(67.6 \%)$ & $68.1 \pm 13.1$ & $30.9 \pm 5.9$ & $108.0 \pm 14.0$ \\
\hline
\end{tabular}

resistance which decreases the levels of the HDL-cholesterol fraction, increases the levels of triglycerides, and leads to the development of arterial hypertension. All of the abovementioned disorders contribute to metabolic syndrome and are related to the development of type 2 diabetes and ischaemic heart disease.

Due to the limitations of BMI methodology, current reports by the World Health Organization and other organizations suggest combining the measurements of BMI and abdominal obesity [11]. The conducted studies have revealed that it is necessary to determine the adipose tissue distribution in the organism.

The aim of our study was to demonstrate a correlation between waist circumference (WC) and body mass index (BMI) in patients with metabolic syndrome in relation to hypertension, lipid disorders, such as atherogenic dyslipidaemia, and carbohydrate disorders, such as impaired fasting glucose or diabetes mellitus type 2 .

\section{Materials and Methods}

A cross-sectional two-site study was conducted in the Kuyavian-Pomeranian Voivodeship for 24 months. The study group consisted of 839 patients with diagnosed metabolic syndrome: 345 men (41.1\%) and 494 women (58.9\%) aged 3280 (Table 1).

Anthropometric measurements (height, weight, and waist circumference) were taken in all subjects. Body mass index (BMI) was calculated as body weight (in kilograms) divided by the square of body height (in metres).

Demographic factors (age, sex, and obesity) and lifestyle factors (smoking habits, physical activity, and alcohol consumption) were determined.

The main analysis was performed using the 2009 revision of the International Diabetes Federation (IDF) definition, requiring the presence of the following criteria:

(i) abdominal obesity: waist circumference of $\geq 80 \mathrm{~cm}$ in women and $\geq 94 \mathrm{~cm}$ in men, measured at the umbilical level in a standing position; (ii) systolic blood pressure (SBP) of $\geq 130 \mathrm{mmHg}$ or diastolic blood pressure (DBP) of $\geq 85 \mathrm{mmHg}$ (or treatment with an antihypertensive medication), measured in all subjects using a validated digital electronic tensiometer in both upper limbs in a seated position after 15 minutes of rest;

(iii) triglycerides levels (TG) of $\geq 150 \mathrm{mg} / \mathrm{dL}(1.7 \mathrm{mmol} / \mathrm{L})$ or statin/fibrate treatment; HDL-cholesterol levels (HDL-C) of $<50 \mathrm{mg} / \mathrm{dL}(1.3 \mathrm{mmol} / \mathrm{L})$ in women and $<40 \mathrm{mg} / \mathrm{dL}(1.0 \mathrm{mmol} / \mathrm{L})$ in men (or statin/fibrate treatment) were measured using an AutoAnalyzer;

(iv) fasting glycaemia of $\geq 100 \mathrm{mg} / \mathrm{dL}(5.6 \mathrm{mmol} / \mathrm{L})$ (or treatment with antidiabetic medications), measured in all subjects with central obesity (WC $>80 \mathrm{~cm}$ in women and $>94 \mathrm{~cm}$ in men). Diabetes was defined as fasting blood glucose (FBG) levels of $\geq 7 \mathrm{mmol} / \mathrm{L}$ and/or treatment with antidiabetic medications.

The study protocol was approved by the Ethics Committee at the University Hospital in Bydgoszcz. All subjects granted their informed consent for participation in the study. Study group characteristics are presented in Table 1.

Metabolic syndrome was identified based on 3 traits in $290(34.6 \%)$ patients, 4 traits in $392(46.7 \%)$ patients, and 5 traits in $157(18.7 \%)$ patients. The characteristics of the study group according to each component of metabolic syndrome are presented in Table 2.

All statistical analyses were performed using the STATISTICA 10.0 software (StatSoft Poland, Bydgoszcz). The Mann-Whitney test, a nonparametric version of Student's $t$ test for independent variables, was used for the comparison. No parametric tests were used in the analyses as for some variables the assumptions of Student's $t$-test regarding normal distribution and variance were not met. The value of Pearson's linear correlation coefficient was determined in the analysis. The results were considered as statistically significant at $P<$ 0.05 . Bilateral test was used to determine the significance of the differences between correlation coefficients. 


\section{Results}

In the study group, waist circumference was found to be significantly correlated with $\mathrm{BMI}(R=0.78, P<0.01)$. The correlation was more pronounced among women $(r=0.80)$ than among men $(r=0.76)$ (Table 3).

Correlation between BMI and waist circumference was analysed according to each component of metabolic syndrome.

3.1. Groups with Arterial Hypertension and Normal Arterial Blood Pressure. A group of patients with arterial hypertension was compared with a group of patients with normal values of arterial blood pressure. It was determined that in the group with arterial hypertension (796; $94.9 \%$ analysed patients), the correlation coefficient $(r=0.79, P<0.05)$ was very similar to that of the entire study group. Conversely, in 43 patients with normal arterial blood pressure the correlation was less pronounced $(r=0.63, P<0.05)$. The difference between the two groups was statistically significant $(0.79$ versus $0.63, P=0.04$ ). Table 4 presents the statistically significant differences between the group of patients with arterial hypertension and the group of patients with normal arterial blood pressure.

Table 5 presents the correlation between BMI and waist circumference according to the presence of arterial hypertension or normotension.

Subsequently, the study group was divided according to subject sex. It was determined that in the subgroup of men with normal arterial blood pressure, the correlation between BMI and WC $(0.67 ; P<0.05)$ was more pronounced than that observed in the subgroup of women with normotension $(0.55 ; P<0.05)$. However, the difference was not statistically significant $(0.55$ versus $0.67 P=0.5632)$.

3.2. Groups with Diabetes Mellitus Type 2 and without Carbohydrate Disorders. Correlation between BMI and WC in the study group with type 2 diabetes, compared to the group without carbohydrate disorders, is presented in Table 6 .

Type 2 diabetes was determined in 491 (58.5\%) patients with metabolic syndrome, while in $110(13.5 \%)$ patients no carbohydrate disorders were found (Table 7).

3.3. Groups of Patients with and without Impaired Fasting Glucose (IFG). In 208 (24.8\%) patients, impaired fasting glucose levels were detected (Table 9).

3.4. Groups of Patients with Decreased Levels of the HDLCholesterol Fraction ( $<50$ in Women and $<40$ in Men) and without Lipid Disorders. In 567 (67.6\%) patients, decreased levels of the HDL-cholesterol fraction were detected (Tables 10 and 11).

3.5. Groups of Patients with Increased Levels of Triglycerides (>150 mg/dL) and Normal TG Levels. In 313 (37.3\%) patients, increased levels of triglycerides (TG) were detected, as opposed to 526 (62.7\%) patients in whom increased TG levels were not observed (Tables 12 and 13).
TABLE 3: Correlation between BMI and WC in the study group according to subject sex.

\begin{tabular}{lccc}
\hline BMI/WC & $n$ & $r$-correlation coefficient & $P$ \\
\hline Total & 839 & 0.78 & $<0.05$ \\
Women & 494 & 0.80 & $<0.05$ \\
Men & 345 & 0.76 & $<0.05$ \\
\hline
\end{tabular}

TABLE 4: Characteristics of patients in the group with arterial hypertension and the group with normal arterial blood pressure.

\begin{tabular}{lccc}
\hline Variables & $\begin{array}{c}\text { Group with } \\
\text { hypertension } \\
(n=796)\end{array}$ & $\begin{array}{c}\text { Group with } \\
\text { normotension } \\
(n=43)\end{array}$ & $P$ \\
\hline Age (years) & $67.9 \pm 12.7$ & $60.7 \pm 15.7$ & 0.003 \\
Body height $(\mathrm{cm})$ & $165.9 \pm 8.6$ & $168.7 \pm 8.2$ & 0.024 \\
Body weight $(\mathrm{kg})$ & $85.0 \pm 18.0$ & $81.2 \pm 12.7$ & 0.167 \\
BMI $\left(\mathrm{kg} / \mathrm{m}^{2}\right)$ & $30.8 \pm 5.7$ & $28.4 \pm 3.3$ & 0.005 \\
WC $(\mathrm{cm})$ & $108.0 \pm 13.7$ & $104.6 \pm 10.2$ & 0.143 \\
MAP $(\mathrm{mmHg})$ & $125.9 \pm 15.7$ & $109.4 \pm 10.6$ & 0.000 \\
\hline
\end{tabular}

\section{Discussion}

Metabolic syndrome (MetS) is a serious public health problem worldwide and its occurrence is increasing $[1,2,10]$. In population studies, the detected MetS occurrence varies between $20 \%$ and $45 \%$ of population. This constitutes a serious social problem as in such patients the risk of cardiovascular diseases increases significantly.

Abdominal obesity is the most frequently observed component of metabolic syndrome. In the NATPOL 2002 study, it was detected in 19\% patients, while in the 2011 NATPOL PLUS study, the percentage increased to $22 \%$ of Polish population. Currently, it is estimated that abdominal obesity is present in approximately 6.5 million residents of Poland, while in the predictions for the year 2035 the value is expected to increase to 10 million.

Obesity is commonly assessed using body mass index (BMI) whose values of $\geq 30 \mathrm{~kg} / \mathrm{m}^{2}$ determine somatic obesity.

In our study, we compared the correlation between BMI and waist circumference in patients with diagnosed metabolic syndrome (Table 8). We distinguished the components of metabolic syndrome according to subject sex. We determined that the correlation between BMI and WC occurred in each of the studied subgroups. The correlation coefficient is the lowest $(r=0.55)$ in the subgroup of women with diagnosed metabolic syndrome including arterial hypertension. This is probably due to the small size of the subgroup $(n=20)$ and lower BMI and WC values versus the subgroup with arterial hypertension (BMI 28.4 versus 30.8 , resp., and WC 104.6 versus 108.0 , resp.).

The results obtained in the study group for both women and men with $\mathrm{BMI}=30 \mathrm{~kg} / \mathrm{m}^{2}$ correlate with waist circumference of $104 \mathrm{~cm}$ in women and $108 \mathrm{~cm}$ in men. According to the IDF criteria 2009 revision, abdominal obesity in the European population is defined as WC of $\geq 80 \mathrm{~cm}$ in women and $\mathrm{WC}$ of $\geq 94 \mathrm{~cm}$ in men. The above-mentioned values 
TABLE 5: Correlation between BMI and waist circumference according to the presence of arterial hypertension or normotension.

\begin{tabular}{|c|c|c|c|c|c|c|}
\hline BMI/WC & \multicolumn{3}{|c|}{ With arterial hypertension } & \multicolumn{3}{|c|}{ With arterial normotension } \\
\hline Total & $n=796$ & $r=0.79$ & $P<0.05$ & $n=43$ & $r=0.63$ & $P<0.05$ \\
\hline Women & $n=471$ & $r=0.81$ & $P<0.05$ & $n=20$ & $r=0.55$ & $P<0.05$ \\
\hline Men & $n=325$ & $r=0.76$ & $P<0.05$ & $n=23$ & $r=0.68$ & $P<0.05$ \\
\hline
\end{tabular}

TABLE 6: BMI to waist circumference ratio according to the presence of type 2 diabetes or no carbohydrate disorders.

\begin{tabular}{llclcr}
\hline BMI/WC & \multicolumn{3}{c}{ Diabetes mellitus type 2 } & \multicolumn{3}{c}{ No carbohydrate disorders } \\
\hline Total & $n=491$ & $r=0.79$ & $P<0.05$ & $n=110$ & $r=0.76$ \\
Women & $n=300$ & $r=0.81$ & $P<0.05$ & $n=66$ & $r=0.79$ \\
Men & $n=191$ & $r=0.78$ & $P<0.05$ & $n=44$ & $r=0.71$ \\
\hline
\end{tabular}

TABLE 7: Characteristics of patients from the study groups with and without diabetes mellitus type 2.

\begin{tabular}{lccr}
\hline Variables & $\begin{array}{c}\text { Group with type 2 diabetes } \\
(n=491)\end{array}$ & $\begin{array}{c}\text { Group with no carbohydrate disorders } \\
(n=110)\end{array}$ & $P$ \\
\hline Age (years) & $70.0 \pm 11.1$ & $63.9 \pm 14.4$ & 0.000 \\
Body height $(\mathrm{cm})$ & $165.2 \pm 8.3$ & $167.1 \pm 8.8$ & 0.002 \\
Body weight $(\mathrm{kg})$ & $85.5 \pm 18.4$ & $84.0 \pm 16.8$ & 0.329 \\
BMI $\left(\mathrm{kg} / \mathrm{m}^{2}\right)$ & $31.2 \pm 5.8$ & $30.0 \pm 5.1$ & 0.002 \\
WC $(\mathrm{cm})$ & $109.3 \pm 13.9$ & $105.9 \pm 12.7$ & 0.001 \\
MAP $(\mathrm{mmHg})$ & $124.4 \pm 15.1$ & $126.0 \pm 17.0$ & 0.460 \\
\hline
\end{tabular}

TABLE 8: BMI to waist circumference ratio according to the presence or absence of IFG.

\begin{tabular}{|c|c|c|c|c|c|c|}
\hline BMI/WC & & IFG prese & & & IFG abser & \\
\hline Total & $n=208$ & $r=0.73$ & $P<0.05$ & $n=631$ & $r=0.80$ & $P<0.05$ \\
\hline Women & $n=113$ & $r=0.78$ & $P<0.05$ & $n=381$ & $r=0.81$ & $P<0.05$ \\
\hline Men & $n=95$ & $r=0.64$ & $P<0.05$ & $n=250$ & $r=0.79$ & $P<0.05$ \\
\hline
\end{tabular}

TABLE 9: Characteristics of patients from the study groups with IFG and without carbohydrate disorders.

\begin{tabular}{lccr}
\hline Variables & $\begin{array}{c}\text { Group with IFG } \\
(n=208)\end{array}$ & $\begin{array}{c}\text { Group without IFG } \\
(n=631)\end{array}$ & $P$ \\
\hline Age (years) & $63.6 \pm 14.8$ & $68.8 \pm 12.0$ & 0.000 \\
Body height $(\mathrm{cm})$ & $167.1 \pm 9.0$ & $165.6 \pm 8.4$ & 0.036 \\
Body weight $(\mathrm{kg})$ & $85.0 \pm 16.4$ & $84.8 \pm 18.2$ & 0.668 \\
BMI $\left(\mathrm{kg} / \mathrm{m}^{2}\right)$ & $30.3 \pm 5.2$ & $30.8 \pm 5.7$ & 0.498 \\
WC $(\mathrm{cm})$ & $106.6 \pm 12.7$ & $108.3 \pm 13.8$ & 0.211 \\
MAP $(\mathrm{mmHg})$ & $126.5 \pm 17.0$ & $124.5 \pm 15.5$ & 0.281 \\
\hline
\end{tabular}

correspond to $\mathrm{BMI}=21,62 \mathrm{~kg} / \mathrm{m}^{2}$ in women and $\mathrm{BMI}=$ $25,84 \mathrm{~kg} / \mathrm{m}^{2}$ in men, respectively. The former value is normal, while in the latter case only the "overweight" criterion is met. A question to consider is whether a revision of the current BMI-based obesity criteria should be made or whether using those criteria in the assessment of abdominal obesity should be abandoned. Aye and Sazali suggest that WC is a better predictor of metabolic risk factors for developing MetS than BMI and propose that metabolic risk factors should be screened in the measured WC value in both genders exceeding $80 \mathrm{~cm}$, regardless of BMI [6]. Similarly, Bouguerra et al. conclude that waist circumference (WC) is a convenient measure of abdominal adipose tissue, which is a diabetes risk factor and is strongly linked to other cardiovascular disease (CVD) risk factors [12]. Other authors conducting studies on other ethnic groups also suggest introducing certain changes regarding the use of BMI. Ko and Tang propose the creation of an intermediate state of high WC, the "central preobesity" for Chinese men with WC of $84-90 \mathrm{~cm}$ and women with WC of $74-80 \mathrm{~cm}$. People with central preobesity, similar to those with overweight (BMI $23-25 \mathrm{~kg} / \mathrm{m}^{2}$ ), already have an increased risk of comorbidities [13]. On the other hand, a number of studies have also shown that BMI is as effective as waist circumference in predicting the development of type 
TABLE 10: BMI to waist circumference ratio according to the decreased levels of the HDL-cholesterol fraction or lack of lipid disorders.

\begin{tabular}{llcccc}
\hline BMI/WC & \multicolumn{3}{c}{ Decreased HDL-cholesterol levels } & & No lipid disorders \\
\hline Total & $n=567$ & $r=0.78$ & $P<0.05$ & $n=272$ & $r=0.79$ \\
Women & $n=361$ & $r=0.80$ & $P<0.05$ & $n=133$ & $r=0.83$ \\
Men & $n=206$ & $r=0.77$ & $P<0.05$ & $n=139$ & $r=0.73$ \\
\hline
\end{tabular}

TABLE 11: Characteristics of patients from the study groups with decreased levels of the HDL-cholesterol fraction and without lipid disorders.

\begin{tabular}{lccc}
\hline Variables & $\begin{array}{c}\text { Group with decreased levels of the } \\
\text { HDL-cholesterol fraction } \\
(n=567)\end{array}$ & $\begin{array}{c}\text { Group without lipid disorders } \\
(n=272)\end{array}$ \\
\hline Age (years) & $68.1 \pm 13.1$ & $66.4 \pm 12.5$ & 0.021 \\
Body height $(\mathrm{cm})$ & $165.6 \pm 8.4$ & $166.9 \pm 8.8$ & 0.035 \\
Body weight $(\mathrm{kg})$ & $85.1 \pm 18.7$ & $84.2 \pm 15.7$ & $30.1 \pm 4.7$ \\
BMI $\left(\mathrm{kg} / \mathrm{m}^{2}\right)$ & $30.9 \pm 5.9$ & $107.6 \pm 12.5$ & 0.665 \\
WC $(\mathrm{cm})$ & $108.0 \pm 14.0$ & $127.3 \pm 16.6$ & 0.920 \\
MAP $(\mathrm{mmHg})$ & $124.0 \pm 15.5$ & & 0.011 \\
\hline
\end{tabular}

TABLE 12: BMI to waist circumference ratio according to the increased levels of triglycerides or lack of lipid disorders.

\begin{tabular}{llcllr}
\hline BMI/WC & \multicolumn{3}{c}{ Increased levels of triglycerides } & & No lipid disorders \\
\hline Total & $n=313$ & $r=0.76$ & $P<0.05$ & $n=526$ & $r=0.80$ \\
Women & $n=151$ & $r=0.76$ & $P<0.05$ & $n=343$ & $r=0.83$ \\
Men & $n=162$ & $r=0.77$ & $P<0.05$ & $n=183$ & $r=0.74$ \\
\hline
\end{tabular}

TABLE 13: Characteristics of patients from the study groups with increased levels of triglycerides and without lipid disorders.

\begin{tabular}{lccc}
\hline Variables & $\begin{array}{c}\text { Group with } \\
\text { increased TG levels } \\
(n=313)\end{array}$ & $\begin{array}{c}\text { Group without } \\
\text { lipid disorders } \\
(n=526)\end{array}$ & $P$ \\
\hline Age (years) & $63.8 \pm 13.7$ & $69.7 \pm 12.0$ & 0.000 \\
Body height $(\mathrm{cm})$ & $168.5 \pm 9.0$ & $164.6 \pm 8.0$ & 0.000 \\
Body weight $(\mathrm{kg})$ & $87.5 \pm 16.8$ & $83.2 \pm 18.1$ & 0.000 \\
BMI $\left(\mathrm{kg} / \mathrm{m}^{2}\right)$ & $30.7 \pm 4.7$ & $30.7 \pm 6.1$ & 0.234 \\
WC $(\mathrm{cm})$ & $108.0 \pm 12.7$ & $107.8 \pm 14.0$ & 0.496 \\
MAP $(\mathrm{mmHg})$ & $124.9 \pm 15.9$ & $125.1 \pm 16.0$ & 0.955 \\
\hline
\end{tabular}

$2 \mathrm{DM}$ and other metabolic disturbances [14-17]. In addition, the Japan Society for the Study of Obesity has reported that BMI may estimate visceral fat measured using computed tomography as robustly as waist circumference and that obesity-related complications increase with BMI values of 25 $[1,18]$.

\section{Conclusions}

(1) There is a strong linear correlation between waist circumference and BMI values.

(2) The presence of overweight in men (BMI 25,84 $\mathrm{kg} / \mathrm{m}^{2}$ ) and even normal body weight in women (BMI $21,62 \mathrm{~kg} / \mathrm{m}^{2}$ ) corresponds to an increased volume of visceral tissue in the abdomen. Introduction of primary prophylaxis in those people to limit the development of diabetes mellitus type 2 and cardiovascular diseases should be considered.

\section{Conflict of Interests}

The authors declare that there is no conflict of interests regarding the publication of this paper.

\section{References}

[1] M. Janghorbani and M. Amini, "Incidence of metabolic syndrome and its risk factors among type 2 diabetes clinic attenders in Isfahan, Iran," Polish Journal of Endocrinology, vol. 63, pp. 372-380, 2012.

[2] R. H. Eckel, S. M. Grundy, and P. Z. Zimmet, "The metabolic syndrome," The Lancet, vol. 365, no. 9468, pp. 1415-1428, 2005.

[3] A. Nikolopoulou and N. P. Kadoglou, "Obesity and metabolic syndrome as related to cardiovascular disease," Expert Review of Cardiovascular Therapy, vol. 10, pp. 933-939, 2012.

[4] C. Y. Wang, T. C. Chang, and M. F. Chen, "Associations between subclinical thyroid disease and metabolic syndrome," Endocrine Journal, vol. 59, no. 10, pp. 911-917, 2012.

[5] V. Altabas, "Drug treatment of metabolic syndrome," Current Clinical Pharmacology, vol. 3, 2012.

[6] M. Aye and M. Sazali, "Waist circumference and BMI cut-off points to predict risk fctors for metabolic syndrome among outpatients in a district hospital," Singapore Medical Journal, vol. 53, pp. 545-550, 2012.

[7] P. Kocełak, J. Chudek, and M. Olszanecka-Glinianowicz, "Prevalence of metabolic syndrome and insulin resistance 
in overweight and obese women according to the different diagnostics criteria," Minerva Endocrinologica, vol. 37, pp. 247254, 2012.

[8] A. M. Lottenberg, M. S. Afonso, M. S. Lavrador et al., "The role of dietary fatty acids in the pathology of metabolic syndrome," The Journal of Nutritional Biochemistry, vol. 23, pp. 1027-1040, 2012.

[9] A. Rachas, C. Raffaitin, P. Barberger-Gateau et al., "Clinical usefulness of the metabolic syndrome for the risk of coronary heart disease does not exceed the sum of its individual components in older men and women. The Three-City (3C) Study," Heart, vol. 98, no. 8, pp. 650-655, 2012.

[10] E. S. Ford, W. H. Giles, and A. H. Mokdad, "Increasing prevalence of the metabolic syndrome among U.S. Adults," Diabetes Care, vol. 27, no. 10, pp. 2444-2449, 2004.

[11] M. Shields, M. S. Tremblay, S. Connor Gorber, and I. Janssen, "Abdominal obesity and cardiovascular disease risk factors within body mass index categories," Health Reports, vol. 23, no. 2, pp. 7-15, 2012.

[12] R. Bouguerra, H. Alberti, H. Smida et al., "Waist circumference cut-off points for identification of abdominal obesity among the tunisian adult population," Diabetes, Obesity and Metabolism, vol. 9, no. 6, pp. 859-868, 2007.

[13] G. T. C. Ko and J. S. F. Tang, "Waist circumference and BMI cutoff based on 10-year cardiovascular risk: evidence for 'central pre-obesity"' Obesity, vol. 15, no. 11, pp. 2832-2839, 2007.

[14] M. Janghorbani and M. Amini, "Metabolic syndrome in type 2 diabetes mellitus in Isfahan, Iran: prevalence and risk factors," Metabolic Syndrome and Related Disorders, vol. 5, no. 3, pp. 243254, 2007.

[15] J. M. Dekker, C. Girman, T. Rhodes et al., "Metabolic syndrome and 10-year cardiovascular disease risk in the Hoorn Study," Circulation, vol. 112, no. 5, pp. 666-673, 2005.

[16] N. Sattar, A. Gaw, O. Scherbakova et al., "Metabolic syndrome with and without C-reactive protein as a predictor of coronary heart disease and diabetes in the West of Scotland Coronary Prevention Study," Circulation, vol. 108, no. 4, pp. 414-419, 2003.

[17] Y. Li, H. Yatsuya, H. Iso, K. Tamakoshi, and H. Toyoshima, "Incidence of metabolic syndrome according to combinations of lifestyle factors among middle-aged Japanese male workers," Preventive Medicine, vol. 51, no. 2, pp. 118-122, 2010.

[18] Examination Committee of Criteria for "Obesity Disease" in Japan and Japan Society for the Study of Obesity, "New criteria for "obesity disease" in Japan," Circulation Journal, vol. 66, pp. 987-992, 2002. 


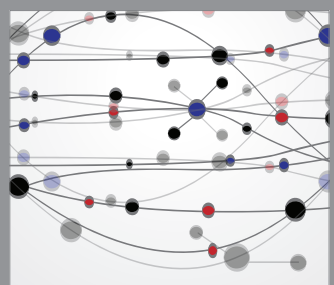

The Scientific World Journal
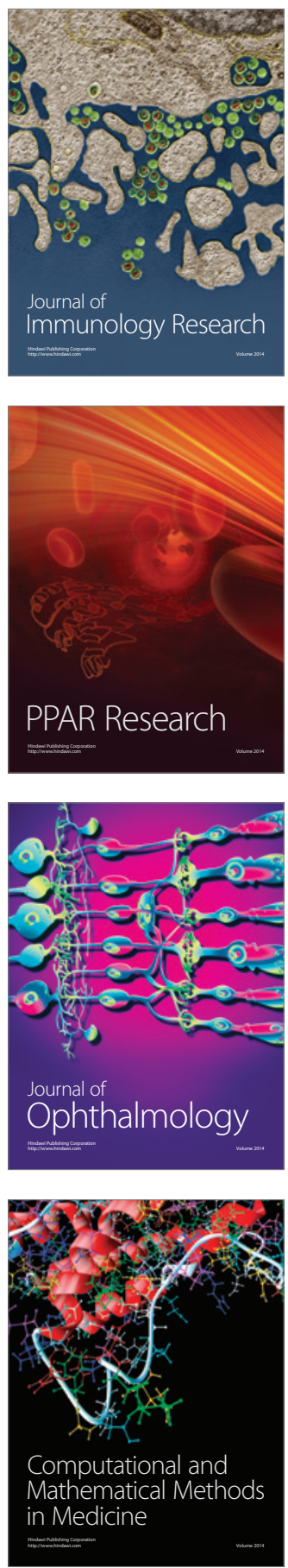

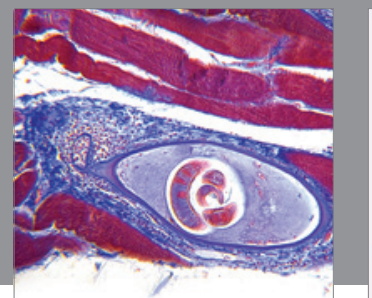

Gastroenterology

Research and Practice
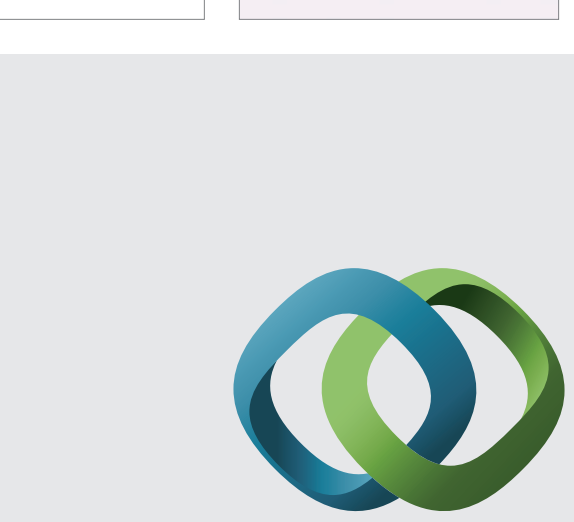

\section{Hindawi}

Submit your manuscripts at

http://www.hindawi.com
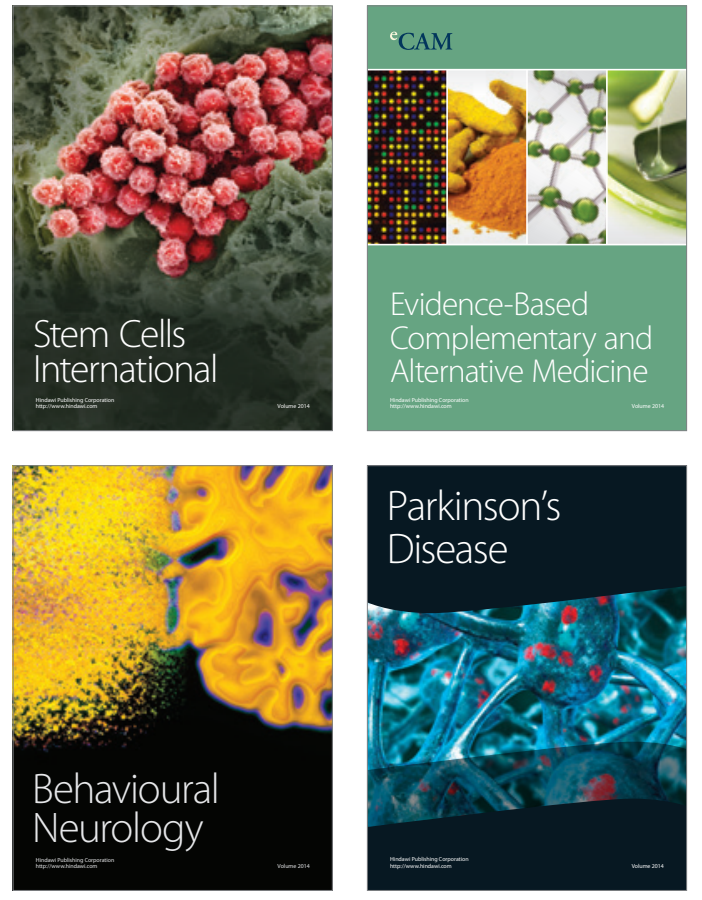
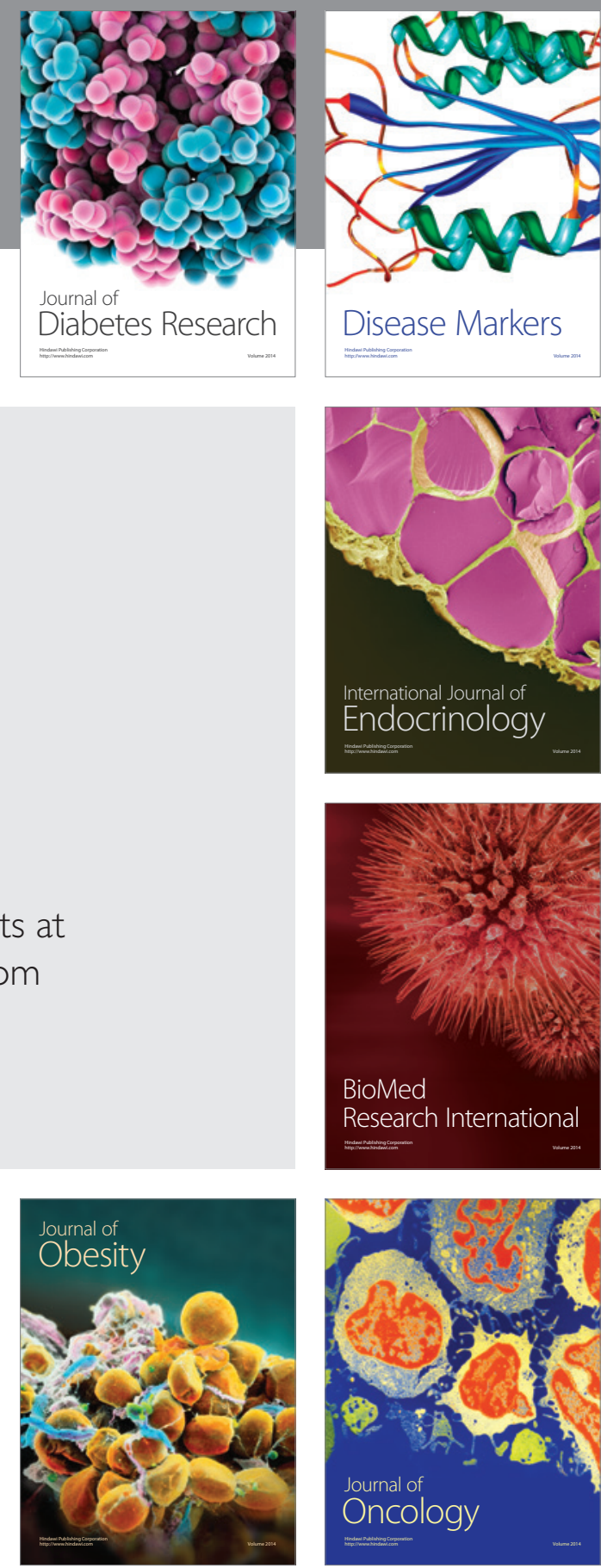

Disease Markers
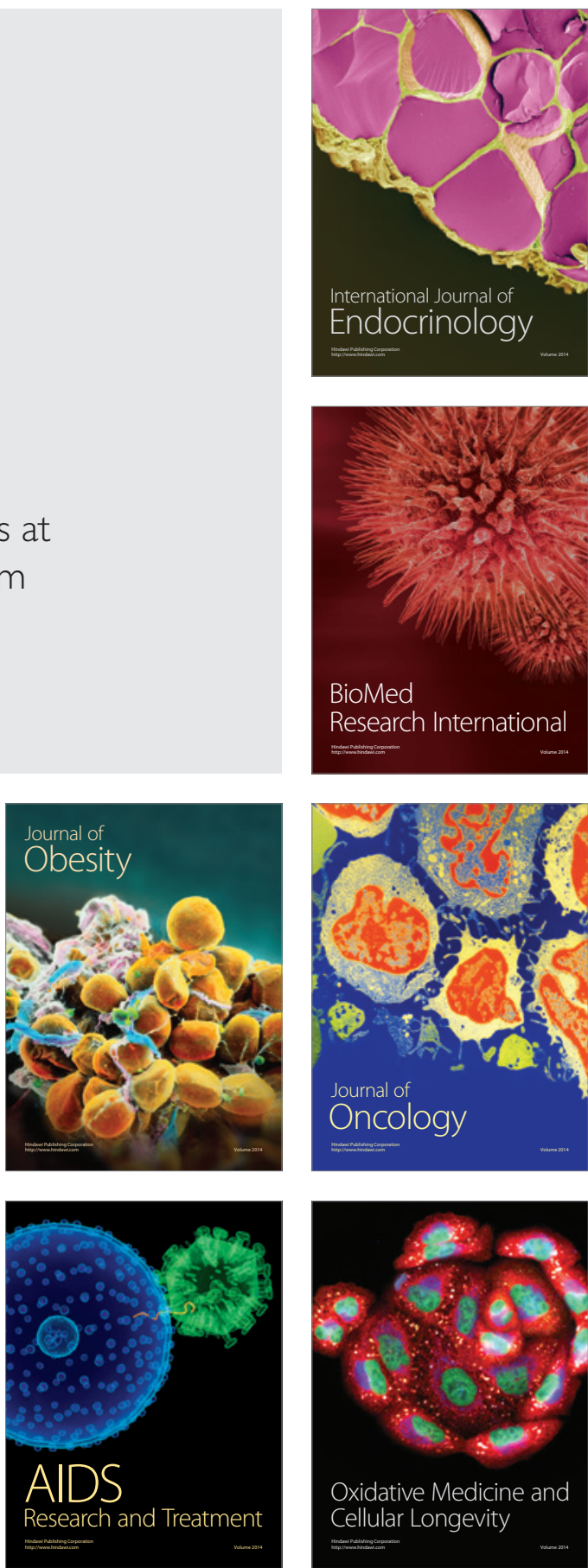